\title{
A study on comparing online, telephone and face to face surveys based on different sampling methods in coffee consumer in Vietnam
}

\author{
Van Dat Tran ${ }^{a^{*}}$ and Lan Anh Lương
}

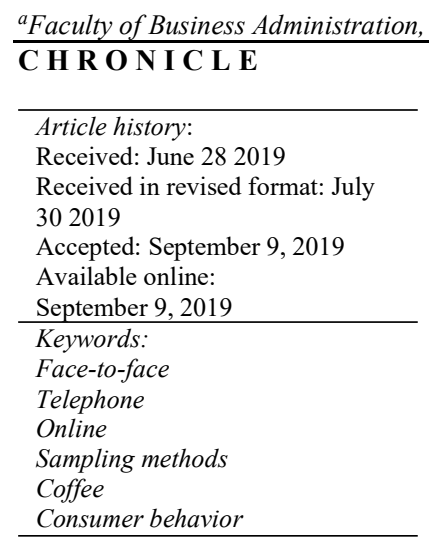

C 2020 by the authors; licensee Growing Science, Canada

\section{Introduction}

The trend of globalization makes the competitions circumstances of domestic enterprises more stressful. Therefore, successful businesses must have extensive knowledge about their customers and their competitors. Market research supports gathering information which would help be aware on how people react to their current potential products and services. Hence, successful companies have comprehensive understanding of their clients and their rivals. More companies around the globe can achieve the benefits they need to innovate, develop and compete with quality information to spark quality ideas. One or all of the possible research and survey approaches as well as experimental studies are used by most marketing scientists and practitioners. Moreover, there are four survey contact methods namely mail, telephone, personal interviews and electronic networks (McDonald \& Adam, 2003). The data collection methods have become increasingly important for understanding the features of these methods at the moment. Therefore, nowadays, many researchers often confused collecting data through web survey when the goal is to generate a representative national sample (Chang \& Krosnick, 2009). In the background of coffee consumer research, there are a diversity of sampling methods used, based on the goal, topic and budget of the survey. Some traditional data collection including face to face, web surveys, telephone, etc. have already been confirmed extremely successful and the results of these types of surveys can be represented as a national behavior or city's residents' behavior. (Szolnoki \& Hoffmann, 2013). Szolnokin and Hoffmann (2013) stated that the results of this study should help to select the mode and interpret the results of face-to-face, telephone or online surveys. Consequently, in this study, we emphasize on comparing three common methods with identical questionnaires used in interviews to analyse the effect of each sampling methods, including recognizing differences in the factors impacting on coffee's consumer behavior and demographic profiles of the respondents across these used modes.

* Corresponding author.

E-mail address: dattv@buh.edu.vn (V. D. Tran) 
We started this study by overviewing the previous comparison studies of modes and highlighting face to face, telephone surveys and online surveys in terms of positive and negative aspects. The next part in this study is the description of study including theoretical basis, methods and material and the results, discussion, which has the goal of highlighting the differences between the selected modes. Finally, in the conclusion, we give an overview of the most important findings and discuss directorial implications of further research.

\section{Literature review}

\subsection{Advantages and disadvantages}

There was a moderate decrease in the number of participants in traditional marketing research caused by rising cost, respondent fears concerning misuse of personal information and managerial issues resulting from the time taken to conduct postal survey (Jarvis, 2002). There are several key strengths in face - to - face surveys such as clearly structured, flexible and adaptable. They are based on personal interaction and can be controlled within the survey environment (Szolnokin \& Hoffmann, 2013). Using online data collection methods in survey research, in particular: lower costs; faster turnaround; higher response levels; lower respondent error; broader stimuli potential through the inclusion of color, graphics and sound; flexibility in the form of adaptive questioning; and even greater enjoyment are the advantages of the sampling method (Forrest, 1999). According to Lazar \& Preece (2002), one of the main advantages of e-mail and web-based surveys is that response times are dramatically reduced. They also noted reduced turnaround time. Allowing researchers to collect data while they work on other tasks may help respondents save their time (Ilieva et al., 2002). Replacing a paper format by an electronic medium could have a researcher cutting down the cost (Bachmann \& Elfrink, 1996; Couper, 2011; Ilieva et al., 2002; Yun \& Trumbo, 2000). The next advantage is recipient acceptance of the format. There are some evidences that the Internet is becoming more acceptable to respondents as a method of collecting data, especially for men (Dillman \& Bowker, 2001) and for people who are college educated (Cartwright et al., 1999). When investigators do online research, they can encounter problems as regards sampling (Andrews et al., 2003; Howard et al., 2001). Moreover, problems like multiple email addresses for the identical person, multiple responses from participants, and invalid/inactive email addresses create sampling on-line a problematic technique (Andrews et al., 2003; Couper, 2011). Posting welcomes to get to potential members in study on community bulletin sheets, discourse groups and chat space is ordinarily utilized by the researchers. Online data collection will suffer from the same disadvantages as the traditional methods. Andrews et al. (2003) illustrated, one of its downsides is to provide researchers with personal information. Sometimes, when they joined an online survey, they could become the goal of illegal activities by invading privacy. Telephone surveys often involve a much lower workforce and can be conducted quicker than the same-sized face-to-face study. According to Szolnoki and Hoffmann (2013), the potential for random digital dialing (RDD), excellent geographic coverage, personal communication and reduced face-to-face study costs add to the benefits of telephone surveys. Telephone interviews in private may also be simpler than face-to-face surveys (Moberg, 1983). Significant potential disadvantages include predisposition to the questioner, reduced response rate and powerlessness to use visual aid (Goldstein \& Jennings, 2002). Another disadvantage reported is that telephone interviews must be kept short of face-to-face interviews (Sweet, 2002), thereby reducing the discussion in depth.

\subsection{Face-to-face versus telephone}

Groves (1979) found that respondents expressed more discomfort over the telephone than face to face when discussing sensitive topics. Interviewers reported that most respondents believe they preferred face-to-face interviews rather than telephone interviews. A major advantage is response rates that tend to be at least 10 percentage points higher for face-to-face surveys than telephone surveys (Aneshensel et al., 1982; Hox \& Leeuw, 1994; Henson et al., 1977). Telephone interviews may be faster paced than face-to-face interviews, it might be advisable to have interviewers occasionally remind respondents to take their time (Marcus \& Crane, 1986). Miller (1995) concludes that telephone interviews are no better or worse than face-to-face interviews. Aquilino $(1992,1994)$ compared a face-to-face survey and telephone interview and found no differences between telephone and face-to-face mode in depression scores. Results recommend that the level of reaction namelessness amid the meeting impacts of respondents' readiness to uncover delicate, individual data. This study did not reveal any significant differences in national overall estimates of several key drinking variables based on interview mode. Besides, Midanik and Greenfield (2003) pointed out there is no significant differences between the telephone and in-person survey data for daily volume. Telephone interviews may provide an opportunity to acquire information from prospective respondents who are unwilling to engage in face-to-face interviews or from communities otherwise hard to access in individual (Tausig \& Freeman, 1988). Telephone interviewing is a cost-effective method of data collection, particularly when compared with face-to-face interviews located in the respondent's normal environment (Tausig \& Freeman, 1988; Aquilino, 1992; Miller, 1995). Generally, we can say that the telephone coverage development over the last three decades has completely changed the status of telephone surveys. The results of the latest surveys no longer show any differences between telephone and face-to-face studies.

\subsection{Face-to-face versus online}

In Newman et al. (2002) research audio-CASI elicited more frequent reporting of "stigmatized behaviors" than face-to-face interviews. Face to face interviewing elicited more frequent reporting "Psychological distress" than audio-CASI. Online ex- 
aminations are regularly directed among board respondents, in contrast to face-to-face interviews. Terhanian (2003)summarized the following problems that could lead to a bias in online panel studies with participants: one can only reach the people on the internet; one can only reach the people who are welcome to respond; and the people who agree to register on the internet boards are frequently young and male. When comparing online and face - to - face methodologies, two main competing effects appear to be at play. Online research using panel approaches seems to attract a more knowledgeable, point - of - view sample compared to face - to - face surveys (Duffy et al., 2005). Moreover, online survey respondents tend to be more politically active, more likely to be earlier adopters of technology, and tend to travel and eat out more than face-to-face survey respondents (Baker et al., 2003). Blasius and Brandt (2010) conducted a stratified online study with 1300 cases in Germany and compared it with a representative face-to-face survey. While both samples were equivalent in terms of age, gender and education, the online sample did not represent the entire population. Lindhjem and Navrud (2011) found that the response rate "don't know" was similar in both modes in their study. The difference in results may have been affected by the different sample sizes and the variation in the topic.

\subsection{Telephone versus online}

Web surveys can attain lower nonresponse rates than other data collection methods (Crawford et al. 2002). In comparing the two samples of Web users, we expected higher response rates to the telephone interview than to the Web survey (Fricker et al., 2005). In the telephone interview, the overall response rate was much higher than the Web survey - response rates for telephone samples were almost double the Web sample response rate. In their comparison of survey modes, Beck et al. (2009) concluded that Web surveys had a higher level of bias compared to conventional RDD telephone surveys, which is why they are not yet in a position to replace telephone surveys. In a study conducted in Germany by Liljeberg and Krambeer (2012), telephone and online surveys on different topics were compared. According to Chang and Krosnick (2009), they found the probability sample to be more representative in terms of demographic variables than the nonprobability sample. Moreover, the telephone survey responses showed more bias in response to social desirability than the Internet survey. These results strongly correlate with the results of Yeager et al. (2011), which established a similar study involving seven non-probability samples of Internet surveys to be compared with telephone and internet survey probability samples.

\subsection{Previous research}

Szolnoki and Hoffmann (2013) analyzed on the basis of Duffy et al. (2005) study the differences between raw face-to-face, telephone and online data. This configuration of the study made it possible to examine four modes. They broke up face to face, using portion testing, mobile and internet board research, and an online survey with snowball examination. As indicated, an online survey can be obtained using quota sampling representing the demographic variables chosen. However, this sampling method needs much more correction or maybe some behavioral variables for quota sampling. Therefore, this sort of sampling technique is inadvisable when used for a representative research. Casler et al. (2013) conducted a face-to-face behavioral task and converted it into an online test. Participants recruited on Twitter, Facebook, and Reddit were contrasted online through Amazon's Mechanical Turk (MTurk) and social media posts. They concluded that internet recruitment and testing for certain behavioral exams could be a valid and sometimes superior partner in the collection of private information. Aquilino (1998) investigated the effects of interview mode on measuring depression in younger adults where samples were drawn from the urban-suburban population of the United States. One of three interview modes in this field experiment was randomly assigned to respondents selected through a probability sample area: self-administered, face-to-face, or telephone. In Viet Nam, there is no comparison of three sampling methods in coffee customer studies (internet surveys, telephone and face-to-face surveys). However, with one sampling method (usually using internet or face-to-face surveys), Vietnamese writers performed a study on variables influencing coffee consumers in Ho Chi Minh City and Ha Noi Capital on coffee usage. In this study, descriptive technique of statistical analysis was used to leverage information from field surveys. The study findings accomplished the objective of identifying the factors affecting young people's pure coffee use conduct in Vietnam.

\subsection{Current state of coffee consumer surveys}

Researchers have used many different sampling methods in coffee consumer studies. The following list may be a non-complete list; the selected studies give associate degree example just for every sampling methodology and we refrain from completeness, since this study focuses on the comparison of different sampling methods. Courville (2003) examined the challenges and considerations in using sustainability indicators for comparison purposes, using coffee supply chains in Mexico and Costa Rica as case studies. A paper by Lewis and Runsten (2008), based on a case study conducted in Oaxaca in 2004, examined the links between low coffee prices, migration and certified coffee production and trade. Aguirre (2016) conducted a telephone survey $(n=1,328)$ in the province of San Jose by considering the role of culture. Linton (2005) argued that one of many efforts aimed at linking social responsibility and market capitalism was the movement to promote sustainable coffee produced. By using a study among individual and institutional customers, Hanspal (2010) performed studies on coffee and tea consumption. Personal interview method was used to guarantee that participants could be approached separately and information gathered rapidly. The five most significant components affecting the purchase of a brand for tea and espresso were taste, quality, flavor, affirmation, and effect on health. Szolnoki and Hoffmann (2013) analyzed the differences between raw face - to - face, telephone and online data based on the study of Duffy et al. (2005). 


\section{Materials and methods}

Before collecting date from three sampling methods, the authors firstly conducted qualitative research with expert interviews. To test the effects of research modes in research into coffee consumers, face to face, telephone surveys and online surveys were administered to the Viet Nam population who were at least 17 years old. The data were collected by conducting face to face interviews with approximately 200 respondents in some coffee shops located in Viet nam. It was decided to collect samplings from one city as respondents were fairly educated. Besides, this was the place that compromise diversified customer behavior in different brands. Online surveys were made by a Google form tool which was launched in some online groups/communities with 150 samplings. The face-to-face study was provided in the same questionnaire. For the sampling, demographic variables were used, such as gender, age, income and occupation. The online survey was based on random sampling. The telephone surveys conducted with nearly 150 respondents, which conducted by supporting from professional market research company. There is the combination of qualitative and quantitative research in this paper. The authors interviewed some 5-10 experts to collect some high-end data for running a qualitative research. After synthesizing the theory, the authors proposed a research model, determining the scale to be used in the model and using qualitative research methods to revise the components that constitute the scale of the factors influencing on coffee consumption. The primary data collected about coffee consumers were analyzed by the SPSS 20 software. An online-survey was conducted to collect the data using a questionnaire in Viet nam. 140 questionnaires were collected 130 responses were found valid. The invalid responds were the ones with less than $50 \%$ of the questions answered. About face to face interviews, the authors conducted the interviews with Banking university students and colleagues. Whereas telephone surveys conducted using the support of market research firms with 130 valid answers. For this comparative study, the authors selected basic demographic and behavioral questions about coffee consumption - questions that had been tested several times before (Hanspal, 2010). First, respondents were asked about coffee consumption frequency. This was followed by questions concerning demographic information (age, income, ...), coffee brands, and where they buy coffee. The demographic data were collected at first. In the questionnaire, the authors used a fivepoint scale from not important at all $(=1)$ to highly important $(=5)$ and constant sum scaling (Malhotra \& Birks, 2007). The research mainly uses SPSS 20.0 to analyze the data in this study. Similar to Mueller et al. (2011) the authors used for ordinal penetration measure, Chi-Square test was implemented to test the differences between the segments in terms of socio-demographics and behavior profiles. For metric responses, factorial analysis of variance was used and post hoc effects (Tukeyb test) were estimated for analyzing the significant differences between the segments. Tukey's test compares the means of all treatments to the mean of any other treatment and is considered the best method available in cases where confidence intervals are desired or sample sizes differ.

\section{Result and discussion}

\subsection{Demographic profile}

After conducting data entry, cleaning and coding of necessary variables, the authors conducted Cronbach's Alpha test to evaluate the scale and Tukey Pest hoc test to explore the differences between these sampling methods about demographic factors and coffee's consumer behavior. The invalid responds are the ones with less than $50 \%$ of the questions answered. About face to face interviews, the author conducted the interviews with Banking university students and colleagues in their home and university (See Table 1).

Table 1

Demographic profile by modes

\begin{tabular}{|c|c|c|c|c|c|}
\hline Characteristics & $\begin{array}{c}\text { Face-to-face } \\
\quad N=130\end{array}$ & $\begin{array}{c}\text { Online quota } \\
\mathrm{N}=130\end{array}$ & $\begin{array}{c}\text { Telephone } \\
\mathrm{N}=130\end{array}$ & $\chi^{2 / \mathrm{df}}$ & df \\
\hline Gender (\%) & & & & 6.685 & 2 \\
\hline Male & 34.6 & 39.2 & 50 & & \\
\hline Famle & 65.4 & 60.8 & 50 & & \\
\hline Age $(\%)$ & & & & 20.420 & 4 \\
\hline $17-27$ years old & 69.2 & 42.3 & 53.8 & & \\
\hline $28-45$ years old & 23.8 & 43.8 & 38.5 & & \\
\hline Over 45 years old & 6.9 & 13.8 & 7.7 & & \\
\hline Job $(\%)$ & & & & 143.476 & 3 \\
\hline Student & 56.9 & 23.8 & 26.9 & & \\
\hline Employed & 32.3 & 66.2 & 19.2 & & \\
\hline Senior citizen & 0 & 0 & 1.5 & & \\
\hline Unemployed & 3.1 & 1.5 & 34.6 & & \\
\hline Entrepreneur & 7.7 & 8.5 & 17.7 & & \\
\hline Income $(\%)$ & & & & 11.924 & 6 \\
\hline$<3.000 .000 \mathrm{VND}$ & 18.5 & 26.9 & 26.2 & & \\
\hline $3.000 .000-7.000 .000 \mathrm{VND}$ & 34.6 & 18.5 & 28.5 & & \\
\hline $8.000 .000-15.000 .000 \mathrm{VND}$ & 22.3 & 32.3 & 25.4 & & \\
\hline$>15.000 .000 \mathrm{VND}$ & 24.6 & 22.3 & 20 & & \\
\hline
\end{tabular}


Among 390 respondents, 161 respondents are males and the same figure for females are 229 respondents. In terms of age, those who are above 17-27 years old accounted for 55.1\% of the sample, ranked the highest. The figures for those aged 28 45 years old and over 45 years old are $35.4 \%$ and $9.5 \%$ respectively. Most of the respondents are employees, with $39.2 \%$ of the sample, the rest are university students in Ho Chi Minh City (35.9\%), unemployed (13.1\%) and business owners (11.3\%). Out of 130 respondents of online surveys, there are 45 respondents with income from 3.000.000 VND to 7.000.000 VND, which is the largest number $(346 \%)$. Whereas in face to face interviews, there are 42 respondents who have $8.000 .000 \mathrm{VND}$ -15.000 .000 VND per months (32.3\%). Telephone surveys have 37 respondents of 130 who earn 3.000.000 VND - 7.000.000 VND per month. It can be seen that there is no relation between frequency, income and Type. Therefore, we can conclude that there is a relationship between Gender, Age, Job and Type.

Table 2

Coffee consumption behavior of the segments

\begin{tabular}{|c|c|c|c|c|c|}
\hline Characteristics & $\begin{array}{c}\text { Online quota } \\
\quad \mathbf{N}=130\end{array}$ & $\begin{array}{c}\text { Face-to-face } \\
\quad \mathbf{N}=130\end{array}$ & $\begin{array}{c}\text { Telephone } \\
\mathbf{N}=130\end{array}$ & $\chi 2 / \mathrm{df}$ & df \\
\hline Frequency (\%) & & & & $4,244^{\mathrm{a}}$ & 6 \\
\hline Regularly & 36.9 & 46.9 & 44.6 & & \\
\hline Sometimes & 43.8 & 34.6 & 39.2 & & \\
\hline Rarely & 16.9 & 14.6 & 13.8 & & \\
\hline Never & 2.3 & 3.8 & 2.3 & & \\
\hline \multicolumn{6}{|l|}{ Coffee brand name (\%) } \\
\hline Nescafe & 23.7 & 26.3 & 21.6 & & \\
\hline Cafe Pho & 10.1 & 10.2 & 12.2 & & \\
\hline Nam Viet blended coffee & 5.8 & 7.8 & 9.4 & & \\
\hline Highland coffee & 29.5 & 22.9 & 21.6 & & \\
\hline Something else & 30.9 & 32.7 & 35.1 & & \\
\hline \multicolumn{6}{|l|}{ Chanel sale $(\%)$} \\
\hline Market & 4.7 & 8.3 & 7.0 & & \\
\hline Supermarket & 38.1 & 35.5 & 31.5 & & \\
\hline Agency & 5.7 & 8.3 & 9.6 & & \\
\hline Grocery & 17.0 & 14.7 & 11.5 & & \\
\hline Retail store & 17.5 & 13.4 & 18.9 & & \\
\hline Somewhere else & 17.0 & 19.8 & 21.5 & & \\
\hline
\end{tabular}

It can be seen in Table 2 that in online surveys, 57 respondents sometimes drink coffee accounted for $43.8 \%$ within date of three sampling methods. Whereas, in Face to face interviews and telephone surveys, respondents drink coffee regularly with $46.9 \%$ and $44.6 \%$ respectively. Nescafe has 49 responses in online surveys (23.7\%) 54 responses in face to face interviews $(23.3 \%)$ and 53 responses in telephone answers (21.6\%). Whereas the Cafe Pho was used by 21 responses in online survey, 21 responses in face to face respondents and 30 telephone answers, accounted for $10.1 \%, 10.2 \%, 12.2 \%$ respectively. Nam Viet blended coffee took the lowest percentage in three methods. Other mentioned coffee brands have the highest proportion in all sampling methods, accounted for $30.9 \%$ in online surveys, $32.7 \%$ in face to face interviews and $35.1 \%$ of telephone survey.

\subsection{One way Anova}

It is believed that when the value of the F-ratio is greater than the appropriate critical F distribution at $=0.05$, the null hypothesis is rejected, it is assumed that at least one of the group means is significantly different from the other group means, and it is valid to proceed with post hoc testing. Following the information, the authors looked at the Sig value in the ANOVA table to know whether or not there is a difference in values medium. It can clear that there are 10 variables (taste, flavor, quality, social concerns, environment concerns, family, peers, supplier Familiarity, supplier reputation, certification) which have the Sig. $>5 \%$ : there is no difference so we cannot continue ANOVA analysis. However, there are a difference in 3 variables such as price, health concerns and promotion schemes variable with the Sig. $<5 \%$ (the level of significance).

\section{Table 3}

Test of Homogeneity of Variances of 13 factors

\begin{tabular}{lcccc}
\hline & Levene Statistic & df1 & df2 & Sig. \\
\hline PRICE & 9.079 & 2 & 387 & .000 \\
QUALITY & .269 & 2 & 387 & .765 \\
TASTE & .968 & 2 & 387 & .381 \\
FLAVOR & .704 & 2 & 387 & .495 \\
ENVIRONMENTAL CONCERNS & 3.384 & 2 & 387 & .035 \\
SOCIAL CONCERNS & 1.501 & 2 & 387 & .224 \\
HEALTH CONCERNS & 10.588 & 2 & 387 & .000 \\
FAMILY & 1.105 & 2 & 387 & .332 \\
PEERS & 3.174 & 2 & 387 & .043 \\
SUPPLIER FAMILIARITY & .890 & 2 & 387 & .411 \\
SUPPLIER REPUTATION & .982 & 2 & 387 & .375 \\
CERTIFACTION & .065 & 2 & 387 & .937 \\
PROMOTION SCHEMES & 2.008 & 2 & 387 & .136 \\
\hline
\end{tabular}


The Promotion schemes factor has the ANOVA Sig. $=0.002<0.05$ and the Sig of Test Homogeneity of Variances $=0.136$ $>0.05$ so there is no difference in variance of variables. However, the health concerns and price variable have the same ANOVA Sig. $=0.000<0.05$ and the Sig of Test Homogeneity of Variances $=0.00<5 \%$ : there is a difference in variance.

Table 4

Multiple Comparisons of Promotion schemes

Dependent Variable: PROMOTION SCHEMES

Tukey HSD

\begin{tabular}{|c|c|c|c|c|c|c|}
\hline \multirow[t]{2}{*}{ (I) TYPE } & \multirow[t]{2}{*}{ (J) TYPE } & \multirow{2}{*}{$\begin{array}{l}\text { Mean Difference } \\
(\mathrm{I}-\mathrm{J})\end{array}$} & \multirow[t]{2}{*}{ Std. Error } & \multirow[t]{2}{*}{ Sig. } & \multicolumn{2}{|c|}{ 95\% Confidence Interval } \\
\hline & & & & & Lower Bound & Upper Bound \\
\hline \multirow{2}{*}{ ONLINE SURVEY } & FACE TO FACE INTERVIEWS & .062 & .138 & .897 & -.26 & .39 \\
\hline & TELEPHONE SURVEY & $.462^{*}$ & .138 & .003 & .14 & .79 \\
\hline \multirow{2}{*}{$\begin{array}{l}\text { FACE TO FACE INTER- } \\
\text { VIEWS }\end{array}$} & ONLINE SURVEY & -.062 & .138 & 897 & -.39 & .26 \\
\hline & TELEPHONE SURVEY & $.400^{*}$ & .138 & 011 & .07 & .73 \\
\hline \multirow{2}{*}{ TELEPHONE SURVEY } & ONLINE SURVEY & $-.462^{*}$ & .138 & .003 & -.79 & -.14 \\
\hline & FACE TO FACE INTERVIEWS & $-.400^{*}$ & .138 & 011 & -.73 & -.07 \\
\hline
\end{tabular}

*. The mean difference is significant at the 0.05 level.

The Multiple Comparisons (Tukey HSD) tables delineated the Sig. value of $0.003<5 \%$ (the level of significance) that is the Sig. when comparing the promotion schemes between two groups: online surveys and telephone surveys. Mean Difference (I-J) of this row is 0.462 which shows the importance mean of online surveys higher than telephone surveys. In addition, since the Sig. Value of $0.011<5 \%$ (the level of significance) there is a difference between telephone surveys and face to face interviews about the importance of promotion schemes influencing on coffee consumption. Mean Difference (I-J) of this row is -0.400 which shows the importance of the mean of telephone surveys lower than the face to face interviews.

\section{Table 4}

Multiple Comparisons of Promotion schemes

\begin{tabular}{|c|c|c|c|c|c|c|c|}
\hline \multicolumn{8}{|l|}{ Dunnett T3 } \\
\hline \multirow{2}{*}{$\begin{array}{l}\text { Dependent } \\
\text { Variable }\end{array}$} & \multirow[t]{2}{*}{ (I) TYPE } & \multirow[t]{2}{*}{ (J) TYPE } & \multirow{2}{*}{$\begin{array}{c}\text { Mean Difference } \\
(\mathrm{I}-\mathrm{J})\end{array}$} & \multirow{2}{*}{$\begin{array}{l}\text { Std. Er- } \\
\quad \text { ror }\end{array}$} & \multirow[t]{2}{*}{ Sig. } & \multicolumn{2}{|c|}{$95 \%$ Confidence Interval } \\
\hline & & & & & & $\begin{array}{l}\text { Lower } \\
\text { Bound }\end{array}$ & $\begin{array}{l}\text { Upper } \\
\text { Bound }\end{array}$ \\
\hline \multirow{6}{*}{ PRICE } & \multirow[t]{2}{*}{ ONLINE SURVEY } & $\begin{array}{l}\text { FACE TO FACE INTER- } \\
\text { VIEWS }\end{array}$ & $-.762^{*}$ & .138 & .000 & -1.09 & -.43 \\
\hline & & TELEPHONE SURVEY & -.208 & .155 & .452 & -.58 & .17 \\
\hline & \multirow{2}{*}{ FACE TO FACE INTERVIEWS } & ONLINE SURVEY & $.762^{*}$ & .138 & .000 & .43 & 1.09 \\
\hline & & TELEPHONE SURVEY & $.554^{*}$ & .133 & .000 & .23 & .87 \\
\hline & \multirow[b]{2}{*}{ TELEPHONE SURVEY } & ONLINE SURVEY & .208 & .155 & .452 & -.17 & .58 \\
\hline & & $\begin{array}{l}\text { FACE TO FACE INTER- } \\
\text { VIEWS }\end{array}$ & $-.554^{*}$ & .133 & .000 & -.87 & -.23 \\
\hline \multirow{6}{*}{$\begin{array}{l}\text { HEALTH } \\
\text { CONCERNS }\end{array}$} & \multirow[t]{2}{*}{ ONLINE SURVEY } & $\begin{array}{l}\text { FACE TO FACE INTER- } \\
\text { VIEWS }\end{array}$ & -.154 & .146 & .645 & -.50 & .20 \\
\hline & & TELEPHONE SURVEY & $-1.108^{*}$ & .133 & .000 & -1.43 & -.79 \\
\hline & \multirow{2}{*}{ FACE TO FACE INTERVIEWS } & ONLINE SURVEY & .154 & .146 & .645 & -.20 & .50 \\
\hline & & TELEPHONE SURVEY & $-.954^{*}$ & .118 & .000 & -1.24 & -.67 \\
\hline & \multirow[b]{2}{*}{ TELEPHONE SURVEY } & ONLINE SURVEY & $1.108^{*}$ & .133 & .000 & .79 & 1.43 \\
\hline & & $\begin{array}{l}\text { FACE TO FACE INTER- } \\
\text { VIEWS }\end{array}$ & $.954^{*}$ & .118 & .000 & .67 & 1.24 \\
\hline
\end{tabular}

*. The mean difference is significant at the 0.05 level.

Multiple Comparisons (Dunnett T3) demonstrated the Sig. value of $0.00<5 \%$ (the level of significance) that is the Sig. when comparing the promotion schemes between two age groups: online surveys and face to face interviews. Mean Difference (I$\mathrm{J}$ ) of this row is -0.762 which shows the importance mean (Price) of online surveys lower than face to face interviews. Moreover, based on the Sig. Value of $0.00<5 \%$ (the level of significance) there is a difference between face to face interviews and telephone surveys about the importance of promotion schemes influencing on coffee consumption. Mean Difference (I$\mathrm{J})$ of this row is 0.554 which shows the importance mean (Price) of face to face interviews higher than telephone surveys.

Table 6

Overview of the strengths and weakness of the sampling methods

\begin{tabular}{lccc}
\multicolumn{1}{c}{ Variable } & Online surveys $(\mathrm{n}=130)$ & Face to face interviews $(\mathrm{n}=130)$ & Telephone surveys $(\mathrm{n}=130)$ \\
\hline Gender & Bias - toward female & Bias - toward female & Equal \\
Age & Bias - toward 17-27 years old & Bias- toward 28-45 years old & Bias - toward 17-27 years old \\
Job & Bias - toward student & Bias - toward employed and students & Bias - toward unemployed and entrepreneur \\
Income & No bias & No bias & No bias \\
Fequency & No bias & No bias & No bias \\
Use of sale channels & No bias & No bias & No bias \\
Brand name & No bias & No bias & No bias \\
\hline
\end{tabular}

About health concerns variable, it can be seen that the Sig. value of $0.00<5 \%$ (the level of significance) that is the Sig. when comparing the promotion schemes between two age groups: online surveys and telephone surveys. Mean Difference (I-J) of 
this row is -1.108 which shows the importance mean (Health Concerns) of online surveys lower than telephone surveys. The Sig. Value of $0.00<5 \%$ (the level of significance) means there is a difference between telephone surveys and face to face interviews about the importance of promotion schemes influencing on coffee consumption. Mean Difference (I-J) of this row is 0.954 which shows the importance mean (Health concerns) of telephone surveys higher than face to face interviews. In summarizing the study results in Table 6 , the author is unable to say which of the studies clearly yielded representative results without any bias. Firstly, the telephone surveys performed better because it approached many genders so it will have an overview about the coffee consumer within gender. Interestingly, a gender difference in interviewer strategy was found in the face-to-face interview, but not the telephone interview, such that the response rate of male applicants was significantly lower than female applicants in face-to-face interviews. Whereas, face to face interviews are difficult to conduct by their weakness such as geographical distance. With respect to occupation, the face-to-face surveyed individuals with university degrees, employees and students. The Internet-based sample was more representative of the nation's population over 17 years than the telephone or face to face sampling method. Online surveys attracted many youngsters from 17-27 years old who are students. Generally, we can note that face-to-face interviews evaluated all of the statements at a significantly lower level than the other respondents. The authors assumed that this outcome was closely related to individual involvement. About 13 factors impacting coffee consumer, there are differences in the answers of three sampling methods. 3 variables within 13 variables are Price, health concerns and promotion schemes. Firstly, the author mentioned the differences of the answers about Price. In online surveys, the respondents thought Price is less important than the face to face interviews. Whereas the respondents of face to face interviews answered the factor "Price" is more important than telephone surveys. About health concerns variable, the respondents of online surveys answered this factor is less important than the respondents of telephone surveys. Face to face interviews respondents replied that this factor is less important than telephone survey respondents.

\section{Conclusion and managerial implication}

When comparing online, telephone and face-to-face sampling methods, this research have seen a range of results. Firstly, telephone is the best choice when marketers conducting coffee market research because of its flexibility and effectiveness. Online research attracted a more knowledgeable, viewpoint-orientated sample than face-to-face surveys. However, cell phones have made telephone communication an even larger part of everyday culture and could make it even more accessible to coffee consumers. The three surveys achieved different contact, cooperation, and overall response rates. The results of consumer survey confirm the association of telephone access with age and occupation. It can be seen that entrepreneurs and unemployed have more free time to participate surveys on telephone. Other reasons given for choosing a telephone interview were the lack of transportation for a visitor, or the visitor had to look after kids. This finding confirms the findings of Fenig et al. (1993) who found that telephone interviewing allows the interviewer access to respondents who are hard to reach because of work schedules. Genders of respondents were not associated with telephone access. The reason is because man and women have telephones that means there is no differences about response rate. There is no significant difference in the values of respondents in these three surveys. The authors also found that when buying coffee, there are no significant differences in the use of sales channels. However, there are significances in the importance of 13 factors influencing coffee consumption in three sampling methods. Data of the face to face interviews showed the factor "Price" was more important than online surveys because participants of face to face interviews were mostly students and employed. Whereas, the telephone respondents illustrated that the factor "Health concerns" was more important than the others. There are some reasons about the differences. Firstly, in face to face interviews, the interviewers have more time to explain and deep discussion with respondents which means they have enough time and understanding about the factors to evaluate how important it was. While in telephone surveys, the respondents usually interrupt or try to answer quickly so the interviewers do not have time and chances to explain the term and meaning of the factors. This study approaches some new aspects compared with previous research (Szolnoki \& Hoffmann, 2013; Duffy, 2005) Firstly, this study conducted the comparison of three sampling methods namely telephone surveys, face to face interviews and online surveys in coffee consumers. Therefore, this study also recommended with the large sample should use telephone surveys because telephone surveys will include the demographical requirements such as gender, job, age, etc. In addition, market research about coffee consumption normally asked many deep questions about coffee which definitely need the explanation from the interviewers. In Viet Nam, there are no research about the comparison among the three sampling methods to choose the most effective to conduct coffee consumption. Based on the results of this study, the authors proposed some recommendations as follows:

Through the data survey of customers who are consuming coffee, the authors have studied many different issues related to the level of the importance of 13 factors influencing coffee consumption within three sampling methods. These online surveys provide an extremely efficient method for collecting survey data compared with traditional survey methods (i.e. mail/ surveys, personal interviews) and telephone surveys. However, telephone surveys are able to approach people who are from 28- over 45 years old and employees/entrepreneurs, the main population consuming coffee. Online surveys are suitable for the younger and internet users. Therefore, administrators need to choose the most efficient sampling methods to conduct their research before starting colleting the data. Secondly, the company should invest more in research and development to provide specialized, innovative and optimal features and services to enhance customer satisfaction and create a competitive advantage. Moreover, the company should invest more in research before choosing sampling methods to provide specialized, innovative and optimal features and services to enhance valuable answers and create a competitive advantage for their company. In addition, 
managers should emphasize on 3 important factors impacting on coffee consumers purchase decision; namely Price, Promotion schemes and Health concerns. Because there are some differences in the way respondents answers how important of each factor is. Especially, interviews should focus on the explanation about 3 factors to receive the most accurate response in any types of data collection.

\section{Limitations and recommendation for future studies}

Each study has its own results and limitations. This study also has the following limitations: First of all, due to the time and budget constraints of the study, the authors only surveyed 500 respondents who had been consuming coffee by online surveys and face to face interviews in the area of Vietnam. Thus, it is suggested that future scientists investigate potential members in the entire of Vietnam in order to have a view more accurate and more general about sampling methods. Therefore, respondents for this research are almost students and officers who are in center dimension salary gathering. The authors could not interact with ones in high income class. They can have other opinions about experiencing many kinds of e-retailers and concerning authentic products/services. Those opinions can make a contribution to the more objective observations of customer behaviors about e-service aspects. The authors have little indication of whether the differences between telephone, online surveys and face-to-face interviews detected have longer-term impacts in terms of criterion-related and discriminant validity.

\section{Acknowledgement}

The authors would like to thank the anonymous referees for constructive comments on earlier version of this paper.

\section{References}

Aguirre, J. (2016). Culture, health, gender and coffee drinking: A Costa Rican perspective. British Food Journal, 118(1), 150163.

Aquilino, W. S. (1991). Telephone versus face-to-face interviewing for household drug use surveys. International Journal of the Addictions, 27(1), 71-91.

Acquilino, W. S. (1994). Interview mode effects in surveys of drug and alcohol use. Public Opinion Quarterly, 58, $210-240$.

Andrews, D., Nonnecke, B., \& Preece, J. (2003). Electronic survey methodology: A case study in reaching hard-to-involve Internet users. International journal of human-computer interaction, 16(2), 185-210.

Aneshensel, C. S., Frerichs, R. R., Clark, V. A., \& Yokopenic, P. A. (1982). Measuring depression in the community: a comparison of telephone and personal interviews. Public Opinion Quarterly, 46(1), 110-121.

Aquilino, W. S. (1998). Effects of interview mode on measuring depression in younger adults. Journal of Official Statistics, 14(1), 15.

Bachmann, D., Elfrink, J., \& Vazzana, G. (1996). Tracking the progress of e-mail vs. snail-mail. Marketing Research, 8(2), 30.

Baker, K., Curtice, J. \& Sparrow, N. (2003). Internet Poll Trial: Research Report.

Beck, K. H., Yan, A. F., \& Wang, M. Q. (2009). A comparison of web-based and telephone surveys for assessing traffic safety concerns, beliefs, and behaviors. Journal of Safety Research, 40(5), 377-381.

Blasius, J., \& Brandt, M. (2010). Representativeness in online surveys through stratified samples. Bulletin of Sociological Methodology/Bulletin de Méthodologie Sociologique, 107(1), 5-21..

Cartwright, D. W., Thompson, R. J., Poole, M. C., \& Kester, D. D. (1999). Assessing Distance Learning Using a Website Survey. AIR 1999 Annual Forum Paper.

Casler, K., Bickel, L., \& Hackett, E. (2013). Separate but equal? A comparison of participants and data gathered via Amazon's MTurk, social media, and face-to-face behavioral testing. Computers in human behavior, 29(6), 2156-2160.

Chang, L., \& Krosnick, J. A. (2009). National surveys via RDD telephone interviewing versus the Internet: Comparing sample representativeness and response quality. Public Opinion Quarterly, 73(4), 641-678.

Crawford, S., McCabe, S., Couper, M., \& Boyd, C. (2002, August). From mail to web: improving response rates and data collection efficiencies. In International Conference on Improving Surveys (pp. 25-28).

Couper, M. P. (2011). The future of modes of data collection. Public Opinion Quarterly, 75(5), 889-908..

Courville, S. (2003). Use of indicators to compare supply chains in the coffee industry. Greener Management International, 43, 93-105.

Duffy, B., Smith, K., Terhanian, G., \& Bremer, J. (2005). Comparing data from online and face-to-face surveys. International Journal of Market Research, 47(6), 615-639.

Dillman, D. A. (2000). Mail and Internet Surveys: The Tailored Design Method. John Wiley \& Sons. Inc., New York: NY, Washington State University.

Dillman, D. A., \& Bowker, D. K. (2001). The web questionnaire challenge to survey methodologists. Online social sciences, 53-71.

Fenig, S., Levav, I., Kohn, R., \& Yelin, N. (1993). Telephone vs face-to-face interviewing in a community psychiatric survey. American Journal of Public Health, 83(6), 896-898.

Fricker, S., Galesic, M., Tourangeau, R., \& Yan, T. (2005). An experimental comparison of web and telephone surveys. Public Opinion Quarterly, 69(3), 370-392. 
Forrest, E. (1999). Internet Marketing Research, McGraw-Hill, Sydney.

Goldstein, K. M., \& Jennings, M. K. (2002). The effect of advance letters on cooperation in a list sample telephone survey. The Public Opinion Quarterly, 66(4), 608-617.

Groves, R. M. (1979). Actors and questions in telephone and personal interview surveys. Public Opinion Quarterly, 43(2), 190-205.

Hanspal, S. (2010). Consumer Survey on Sustainable Tea \& Coffee Consumption. New Delhi: Partners in Change.

Henson, R., Roth, A., \& Cannell, C. F. (1977). Personalversus telephone interviews: The effects of telephonereinterviews on reporting of psychiatric symptomatology.In National Center for Health Services Research ReportSeries, Experiments in interviewing techniques: Fieldexperiments in health reporting, 1971-1977), 205-219

Hippler, H. J., Schwarz, N., \& Sudman, S. (Eds.). (2012). Social information processing and survey methodology. Springer Science \& Business Media.

Hox, J. J., \& De Leeuw, E. D. (1994). A comparison of nonresponse in mail, telephone, and face-to-face surveys. Quality and Quantity, 28(4), 329-344.

Howard, P. E., Rainie, L., \& Jones, S. (2001). Days and nights on the Internet: The impact of a diffusing technology. American Behavioral Scientist, 45(3), 383-404.

Jarvis, S. (2002). CMOR finds survey refusal rate still rising. Marketing News, 36(3), 4.

Lazar, J., \& Preece, J. (2002). Social considerations in online communities: Usability, sociability, and success factors. na.

Lewis, J., \& Runsten, D. (2008). Is Fair Trade-organic coffee sustainable in the face of migration? Evidence from a Oaxacan Community. Globalizations, 5(2), 275-290.

Ilieva, J., Baron, S., \& Healey, N. M. (2002). Online surveys in marketing research. International Journal of Market Research, 44(3), 1-14.

Liljeberg, H., \& Krambeer, S. (2012). Bevölkerungs-repräsentative Onlinebefragungen. Die Entdeckung des Scharzen Schimmel.

Linton, A. (2005). Partnering for sustainability: business-NGO alliances in the coffee industry. Development in Practice, 15(3-4), 600-614.

Lyberg, L., \& Kasprzyk, D. (2004). Data collection methods and measurement error: an overview. Measurement errors in surveys, 235-257.

Lindhjem, H., \& Navrud, S. (2011). Are Internet surveys an alternative to face-to-face interviews in contingent valuation?. Ecological economics, 70(9), 1628-1637.

Maguire, K. B. (2009). Does mode matter? A comparison of telephone, mail, and in-person treatments in contingent valuation surveys. Journal of environmental management, 90(11), 3528-3533.

Malhotra, N., \& Birks, D. (2007). Marketing Research: an applied approach: 3rd European Edition. Pearson education.

Marcus, A. C., \& Crane, L. A. (1986). Telephone surveys in public health research. Medical Care, 24(2), 97-112.

McDonald, H., \& Adam, S. (2003). A comparison of online and postal data collection methods in marketing research. Marketing intelligence \& planning, 21(2), 85-95.

Miller, C. (1995). In-depth interviewing by telephone: Some practical considerations. Evaluation \& Research in Education, 9(1), 29-38.

Midanik, L. T., \& Greenfield, T. K. (2003). Telephone versus in-person interviews for alcohol use: results of the $2000 \mathrm{National}$ Alcohol Survey. Drug and alcohol dependence, 72(3), 209-214.

Moberg, D. P. (1983). Identifying adolescents with alcohol problems. A field test of the Adolescent Alcohol Involvement Scale. Journal of Studies on Alcohol, 44(4), 701-721.

Newman, J. C., Des Jarlais, D. C., Turner, C. F., Gribble, J., Cooley, P., \& Paone, D. (2002). The differential effects of faceto-face and computer interview modes. American journal of public health, 92(2), 294-297.

Szolnoki, G., \& Hoffmann, D. (2013). Online, face-to-face and telephone surveys-Comparing different sampling methods in wine consumer research. Wine Economics and Policy, 2(2), 57-66.

Sweet, L. (2002). Telephone interviewing: is it compatible with interpretive phenomenological research?. Contemporary Nurse, 12(1), 58-63.

Terhanian, G. (2003). The unfulfilled promise of internet research. In MRS Conference Paper (Vol. 37)

Tausig, J. E., \& Freeman, E. W. (1988). The next best thing to being there: Conducting the clinical research interview by telephone. American Journal of Orthopsychiatry, 58(3), 418-427.

Yeager, D. S., Krosnick, J. A., Chang, L., Javitz, H. S., Levendusky, M. S., Simpser, A., \& Wang, R. (2011). Comparing the accuracy of RDD telephone surveys and internet surveys conducted with probability and non-probability samples. Public opinion quarterly, 75(4), 709-747.

Yun, G. W., \& Trumbo, C. W. (2000). Comparative response to a survey executed by post, e-mail, \& web form. Journal of computer-mediated communication, 6(1), JCMC613. 
(C) 2020 by the authors; licensee Growing Science, Canada. This is an open access article distributed under the terms and conditions of the Creative Commons Attribution (CCBY) license (http://creativecommons.org/licenses/by/4.0/). 